\title{
Inclusion at University: Can we do more than open the door?
}

\author{
Dr John O'Rourke \\ Edith Cowan University
}

\begin{abstract}
The inclusion of students with Intellectual and Developmental Disabilities (IDD) in university settings is an emerging policy initiative. Different models have evolved to support the inclusion of students with IDD in university settings from full inclusion to specialized separate programs. This paper reports the process of creating a program of inclusion for a student with IDD in a Western Australian university. Based on extensive field notes and interviews with the included student and her mentors, the author seeks to assess the pilot study using a case study approach and reflect on what might be required by university staff to enhance inclusive practice for these students.
\end{abstract}

Key words: Social inclusion, academic inclusion, university, inclusive pedagogy, intellectual and developmental disability.

\section{Introduction}

The inclusion of students with intellectual and developmental disabilities (IDD) into universities, although uncommon (Grantley, 2000) appears to be gaining interest worldwide (Gibson, 1997; Hughson, Moodie \& Uditsky, 2006; Martinez \& Queener, 2010; O’Brien, Shevlin, O’Keefe, Fitzgerald, Curtis \& Kenny, 2009; Saloviita, 2000). At face value such inclusion is at odds with a university's traditional function: to provide higher education for the intellectual elite; however, projects such as the 'Up the Hill' project at Flinders University in South Australia have yielded positive outcomes for students with IDD and have run successfully for over a decade now. In Canada too, alternative entrance programs for students with IDD have a relatively long history (Weinkauf, 2001) and these programs are increasingly being accepted as a part of the tertiary educational landscape (Uditsky \& Hughson, 2007). Various 
Inclusion at university

programs have also been established in the United States of America, Ireland and Finland.

Generally, Post-Secondary Inclusion Programs (PSIP) within universities follow three models: First, a full-inclusion model following the principles of social role valorization (Wolfensberger, 2000) as evident in the 'Up the Hill' project (Flinders University), along with the University of Alberta and British Columbia. These programs are focused on individual choice, whereby students with IDD 'audit' units of interest and work towards a 'Certificate of Recognition' from the university. The unit auditor pathway involves student enrollment on a non-credit basis and provides a 'gateway' of engagement for all community members (Hart, Grigal, Sax, Martinez \& Will, 2006). Programs such as 'Up the Hill' are supported by close links with parents, coordination of efforts by specifically employed personnel and the efforts of voluntary mentors (Grantley, 2000).

Second, separate programs are established within a university setting and are made up exclusively of students with disabilities. Such programs, like that at George Mason University, are developed as both post-school academic pathways for individuals with IDD and also provide opportunities for university enrolled pre-service teachers and health professionals to develop skills in working with these individuals.

Third, models such as the Trinity College program at the University of Dublin have developed as hybrids of the first two PSIPs (O'Brien, 2010). In such programs students with IDD work within specifically developed modules, but also engage in research projects in areas of interest and subsequently attend lectures in a diverse range of subject areas away from their set program.

All of these approaches provide opportunities for students with IDD in an environment traditionally inaccessible to them. This inaccessibility within tertiary environments has stemmed from the historical notion that universities are elitist organizations (Gibson, 1997). In some respects this sets them apart from primary and secondary school environments, which along with specialty Technical and Further Education (TAFE) courses have steadily increased numbers of students with disabilities (O'Brien, 2010; State School Teachers Union of WA inc., 2011). The message that is generally delivered from universities is that this environment is restricted to a certain type of person, thus denying opportunities for all students.

On reflection, this denial of opportunities for students with IDD appears to be at odds with current policy direction of Australian universities. The Review of Australian Higher Education (The Bradley Review, 2009), supports the breaking down of "barriers that have led to an ongoing under-representation in higher education of students from low socio-economic status (SES) backgrounds" (Transforming Australia's Higher Education System, 2009, p.2). Considerable incentives are being offered to universities, to enhance 'national productivity', and develop improved 'social inclusion', and by 2020, a target of '20 per cent of higher education enrolments at undergraduate level from low SES backgrounds' has been set. Achieving these figures means the 'exclusivity' of universities will need to change. How much change is required to achieve this goal is an area of concern (Massaro, 2009); but it would appear evident that in the future a stronger sense of inclusion will be required in the tertiary sector. Notwithstanding, providing opportunities for individuals with IDD with the necessary academic and social modifications, is a quantum shift in thinking for many current university academics.

The following paper explores the process and ultimate inclusion of Belle, ${ }^{*}$ a young woman with Down Syndrome, at Edith Cowan University (ECU), Perth, Western Australia during 2008/9. The paper describes the process and preliminary 
Inclusion at university

findings of including this young person into a $3^{\text {rd }}$ Year education unit in Semester 2, 2009. The author kept careful records on the process of connecting the student within the university framework and the experience of including and supporting her during her initial semester at university.

As a senior lecturer and researcher in the mechanisms that support inclusion (O'Rourke, 2005; O'Rourke \& Houghton, 2006; O'Rourke \& Houghton, 2008; O'Rourke \& Houghton, 2009), the author was disposed toward providing post-school educational opportunities for all students and was optimistic that Belle's inclusion would result in enlightening experiences for other enrolled students.

The study uses a case study analysis of Belle's inclusion focusing on three clear areas to provide a strong narrative for this experience. Using a formal approach to the organisation of the narrative (Coffey \& Atkinson, 1996) this paper presents a beginning, middle and end through; firstly, a detailed account of the administrative process prior to Belle's university experience; secondly, firsthand accounts of Belle's inclusion via the author, university mentors and the student herself and finally, a reflection on the experience using a structured examination of four central research questions:

- Did the inclusion program encourage Belle's attendance at lectures/tutorials throughout the semester?

- Did the inclusion program provide opportunities for Belle able to engage in tutorial activities and modified assessments?

- Did the inclusion program provide the impetus for Belle to successfully complete an end of unit project?; and

- What evidence exists that the inclusion program was a positive social and learning experience for Belle?

\section{Method}

In mid 2008, the proposal to include Belle, a student with an IDD, into university lectures and tutorials was presented to staff working in the Special Education program at Edith Cowan University (ECU), Perth, Western Australia. Data were collected from the inception of the proposal through to Belle's eventual inclusion in Semester 2, 2009, via extensive field journals by the author and interviews with fellow students who worked closely with Belle (herein known as mentors). At the completion of Semester 2, 2009, a review was conducted that focussed on Belle's experience, and through this analysis sought to establish structures and protocols for the inclusion of other students with IDD at the university.

Belle was interested in pursuing post-secondary education and working towards becoming an Education Assistant or helper within a school. Two independent inclusion consultants with extensive experience in creating positive opportunities for individuals with IDD put forward the proposition of including Belle at ECU. One of the key elements of this proposal was that Belle would enter as a unit auditor, rather than through direct entry or alternative pathways. As an auditor Belle would pay an auditor's fee and attend university courses of her interest.

Belle's secondary school experience had been within a private co-educational school. Although generally positive, this experience included intermittent periods of home schooling by her Mother. Overall Belle felt ambivalent about her schooling stating that she sometimes felt excluded and was given restricted opportunities.

In recent times Belle's mother had passed away and, as with all young people, Belle's loss of her mother was significant, particularly as she had no immediate 
Inclusion at university

family in Perth. Belle lived independently, with occasional support, in a southern suburb $70 \mathrm{kms}$ away from the university. Belle could be described as gregarious, fun loving, social and in many situations confident. She had previously given talks to interest groups on inclusion.

The six university mentors were students in their $3^{\text {rd }}$ year of a secondary education course. These students were required to complete 20 hours of community service with an agency that supported individuals with disabilities as part of a core diversity course. Those students opted to be university mentors for Belle, in order to accumulate the necessary hours to compete this requirement of the course. Given that there were many community options available to these students, it could be assumed that they were empathetic and supportive of Belle's inclusion. Five of these students were 19-21 years of age, and one was older and a parent of three children.

Casale-Giannola and Kamens (2006) presented a review of the experience of including a student with an IDD at university in the United States in which a single mentor was used for support. This individual was surprised by the level and intensity of support required and suggested 'having two peer support individuals would have been more appropriate' (p.350). Mindful of this result, several mentors provided a team approach to support for Belle.

\section{Getting to know Belle}

Following the initial emails and phone calls of introduction about the proposal, a meeting was convened with Belle and her supporters. After meeting Belle and witnessing her enthusiasm for attending ECU, I felt encouraged to facilitate her inclusion. Soon after this meeting, a date was organized for Belle to attend a trial lecture and tutorial in a core secondary unit: EDS3103: Diversity and Inclusivity in the Secondary Classroom. The class was towards the end of Semester Two, 2008 and it was scheduled so that I was able to determine the logistics of including Belle on a regular basis. The tutorial (the second last of the semester) activity was discussed with Belle, and a DVD to be used in the class was given to her in advance. Students in the tutorial were informed of Belle's upcoming participation, the circumstances behind this and the possible future directions for her.

Belle made her way independently from her residence and met up with a fellow student on the last leg of her trip. She arrived for the lecture and was observed to take down notes and engage in a manner typical of her peers. Belle's involvement in the tutorial was also positive. She introduced herself to the class and appeared comfortable with the discussion taking place. She informed the class that she had Down syndrome and that she understood what students were trying to learn in the course. She was partnered with other students and did not appear intimidated by their discussions. These comments from a fellow tutorial member indicate her capacity to engage:

I was amazed at how well Belle coped with the social experience of university, especially as she was meeting so many people and being passed from one group to the next, she seemed to take it all in her stride and adapted well to all the change.

Following Belle's participation in the lecture and tutorial I approached two students to comment on their experience of class time with her:

Student One: 
Inclusion at university

I enjoyed my morning with Belle. She was polite, well mannered and very interested in everything to do with the university. Belle was not intimidated by the number of people she met at university nor in the size of the campus. I believe she enjoyed the lecture; however I do think it was a little more intimidating that she had expected. She appeared to be relaxed in the tutorial. She responded well when asked questions - answering them with confidence and joining in the group activities.

Belle's presence did not compromise the tutorial. In fact, I believe that her presence enhanced my learning. When learning about difference and disability, it is always easier to remove oneself from the immediate subject; to be confronted with difference and disability ensures we think about it more critically. Belle would have been able to give more insight into how it feels to be different, and to be treated differently.

Student Two:

My interactions with Belle were all positive; she is definitely an amazing young lady, although I did get the impression that she was still finding her feet and path as all 21 year-olds are.

On the strength of my own observations, positivity both from Belle and those who worked with her, further plans for Belle's inclusion were explored.

\section{Preparing for Belle: The process of inclusion}

In an attempt to gain administrative support for Belle's participation beyond the oneoff tutorial, I engaged the Head of the School of Education and Director of the Secondary Program in discussions towards the end of 2008. They were shown the Living the Dream: Inclusive Post-Secondary Education (2006) a DVD about inclusion of students with IDD at the University of Alberta and provided with an overview of the potential directions Belle could take at ECU. Both were supportive of this undertaking and asked that a proposal be drawn-up to seek further support. It was envisaged that official sanction would need to be provided by university administration for Belle's inclusion to be realised. Given we were still in the discussion stage, Belle was contacted and informed that we would now be looking to enroll her in Semester Two 2009 and that more than likely this would occur in the unit she had already sampled: EDS3103: Diversity and Inclusivity in the Secondary Classroom.

EDS3103 was a core unit in which the author was Unit Coordinator. It was a course focused on understanding the historical aspects of disability, legislation as it relates to the area, community agencies that provide support for schools, collaborations necessary in inclusive classrooms, and specific pedagogy required in mixed ability classrooms.

During Semester One 2009, Belle made several visits to the university for meetings with myself and the Secondary Program Director. At all times these meetings were positive, appropriate and encouraging; field notes taken at that time suggested that discussions with Belle about organisational details were time consuming.

During these meetings I gave Belle a description of what to expect at university and what she might gain from participating. Also I provided information about the costs involved, the text book required for the unit, lecture/tutorial times, and how she could achieve course outcomes (including the idea that she would give a presentation rather than complete an exam like other students). Finally, I 
Inclusion at university

explained that a mentor program would be established to support her time at university.

A meeting was then organised with staff from Quality and Equity. They were positive about Belle's inclusion, however, pondered whether real outcomes could be achieved within this environment and whether attempts to include her might be construed as tokenistic. Also, the appropriateness of including a person with Down syndrome in a course titled Diversity and Inclusivity in the Secondary Classroom was queried, and whether she might feel uncomfortable with the unit content.

Without receiving a definite answer from University Executive, I decided to confirm Belle's position as a Unit Auditor and conveyed this to her and her supporters. Modified course materials were sent home to her and student mentors were sought. Following an email to all students enrolled in EDS 3103, six students volunteered to be Belle's mentors over the semester. A meeting was arranged with these students and they were provided with a package of information including published material on the inclusion of students with disabilities at universities.

One week before the second semester was to commence, an email from the University Executive stated that they were uncertain about the inclusion of Belle, and that we were not to proceed with her admission to the unit. With such a short period of time before her commencement in the course, this news was highly concerning, given the level of discussion that had taken place amongst faculty staff, Belle and her supporters. It was then decided that if Belle maintained a position in a voluntary guest role, the same outcomes might be achieved. No official reason was provided about why Belle's inclusion was considered problematic.

\section{Belle's semester experience}

Throughout the semester a field journal was maintained by the author, describing Belle's involvement and how this impacted on her tutorial class. A challenge I experienced throughout the semester was that a major theme of the course was the inclusion of students with disabilities into regular classrooms, and through Belle's inclusion the concept was being practised for the students, as distinct from giving theoretical and rhetorical expression to it.

The following are some observations I made throughout the semester:

July $30^{\text {th }}$ 2009: Opening lecture/tutorial:

Phoned Belle to check on her whereabouts prior to the lecture. She arrived late having asked administrative staff to find the location of her class and not being in the system (which she was annoyed about) she remained lost for some time.

In the time period between the lecture and tutorial Belle stayed with ' $S$ ' a mature-aged student. In her tutorial she introduced herself to the class and openly discussed her disability. During the tutorial she left in tears, describing the whole experience as emotional.

I later spoke to Belle who described the experience as enjoyable, but sad because it was something her Mum would have loved for her. 


\section{$23^{\text {rd }}$ September 2009}

Belle participated well. Her responses were refreshing and natural. After the class she suggested that this was the best experience she had ever had and that she was really starting to learn about university.

After the tutorial, I saw Belle by herself and approached her to see what was going on. Belle's mentors were in the cafe and she was uncertain about going in and sitting with them. I waited with her for over 20 minutes supporting her decisions and negotiating the situation with the other girls. As this was the end of a long day, I left frustrated and feeling 'time poor'.

\section{$14^{\text {th }}$ October, 2009.}

Throughout this session I felt under pressure to engage Belle. This made me feel uneasy, as I was concerned that Belle's inclusion was not going the way I had hoped for.

During discussions about what was expected of her, Belle began to get emotional. Despite my time spent explaining modified course requirements and support from her mentors, Belle was tense and unsure. This post-class conversation with Belle and her mentors went for over 45 minutes and while eventually some positive outcomes were achieved, I felt a sense of pastoral care I had not felt before in a university environment.

Likewise, I left the tutorial feeling somewhat drained and clear that whatever structures were in place for Belle required more clarity if she was to remain positive about this experience. I felt despite modifying the tutorial activities for Belle, accompanying sessions to explain the content more, would assist further.

\section{$26^{\text {th }}$ October, 2009}

For the first time, I left Belle's tutorial feeling good. Perhaps it was because I structured the activity better. During the tutorial session Belle left class and worked with her peers on a final presentation she was going to deliver.

I had emailed Belle's supporters and set an appropriate task for Belle. The tutorial was quite visual and there was a bit for Belle to engage with. I caught a vision of Belle leaving the university - independent and purposeful. It was nice.

\section{$4^{\text {th }}$ November, 2009}

Belle came to my office early for an organised meeting before her class. We spoke about next year and about her final assignment. She was light hearted and appearing to love university. During this discussion inclusion at university seemed very possible.

However, in the two hours between the lecture and tutorial, Belle had a series of disputes with her mentors. The mentors felt she was playing games with them. During this time Belle came to me and asked for help with her assignment and I offered to help her after the tutorial.

Belle did not attend the tutorial. A dispute with her group resulted in the need for a debrief with her mentors. They suggested that Belle had told them she felt 'excluded'. As a group they were upset by this. A bad end to Belle's tutorial experience! 
Inclusion at university

The last contact I had with Belle for the semester was at the University Tavern, after completing her final presentation. It was natural and good fun. While it appeared Belle had grown in her appreciation of university during the semester, my feelings towards her inclusion was a re-awakening that inclusion is both incredible and challenging. As described by Barton (1987); it is a multi-layered happening.

\section{Discussion}

The research questions examined the academic and social outcomes for Belle and peers. The findings present a picture of tertiary inclusion from Belle's viewpoint, along with other participants in the experience.

\section{Did the inclusion program encourage Belle's attendance at lectures/tutorials throughout the semester?}

Belle's inclusion into lectures was positive. Her attendance was consistent, missing two out of twelve classes, not dissimilar to many of her peers. She was generally engaged in active learning. These were the reflections from a classmate who sat near her during this time:

I was lucky enough to sit next to Belle in the lecture and was interested in seeing how she took her notes and processed the information she was given in the lecture. She was better than I was when I started uni at listening to and then summarising the information into notes. I could not have a good look but she definitely got the gist of it.

\section{Did the inclusion program provide opportunities for Belle able to engage in tutorial activities and modified assessments?}

Belle's involvement in tutorial activities were not always successful, despite the tutorial curriculum being modified. At times Belle felt uncomfortable at being challenged academically. This excerpt from my field notes describes one of the tutorials;

I tried to alter the tutorial so it would be more engaging for Belle, but realised that conceptually it was quite advanced. In this activity the tutorial students were asked to modify a series of potential classroom lessons for secondary classroom situations and there seemed to be too much additional scaffolding for Belle to fully engage. Belle's tutorial partner seemed to be under pressure to explain the activity more and I found this distracting.

Lobban (2002) in his review of the 'Up the Hill' Project found that academic staff did not make adaptations to their course material for included students with IDD. A typical response from an academic staff member when asked about whether adaptations were necessary was: "No not really. Participants blended into the class well and were not noticeable; they seemed very keen to learn" (p.6). Likewise, Uditsky and Hughson (2007) and Mosoff, Greenholtz and Hurtardo (2009) in their comprehensive reviews of PSIPs in Canada, claimed that academics generally did not feel required or inclined to adapt material, as described by this lecturer; "I very pointedly decided not to change the way I teach. Fifty five other people in the class had expectations of how things will be run" (Uditsky \& Hughson, 2007, p.62). 
Inclusion at university

A review of academic literature on PSIP revealed that the situations described in many instances were lectures (Grantley, 2000; Lobban, 2002), it would appear tutorial classes may present more challenges. My attempts to engage Belle in some of these classes were difficult, despite discussions prior to class, modified outcomes and consultations with her university mentors. Belle in these situations at times appeared frustrated and anxious. The following from my field notes reflect some of her unease:

After the tutorial we sat down for a while with some of her mentors and discussed her concerns. Belle had been asked to complete a modified version of the main assignment, and she and her mentors were worried about this.

It is clear that only limited generalisations on the inclusion of all students with IDD from this study are possible; given it is simply the observation of one student. Additionally, Belle's participation in a more practical unit may have elicited less concern. However, it seems that including a student like Belle in a university tutorial and relying on voluntary mentors to make ongoing changes is reflective of the inclusive practice sometimes observed in primary and secondary situations, which could be reasonably depicted as assimilation (Slee, 2007). To present over reliance on mentors as best practice appears unsound, and, as such, emphasises the need for thoughtful consideration to be given to tutorial activities when engaging students with IDD in university settings.

While, I had clear goals for Belle's participation in the unit, it was evident that she and her university mentors had unclear expectations both for the tutorial and for her external assessments. In establishing a program for Belle, Casale-Giannola and Kamens (2006) was used as guide towards the 'positives and pitfalls' that could occur. Despite being aware of challenges and establishing plans to potentially address these, some of the difficulties observed by Casale-Giannola and Kamens in regard to voluntary support became evident during the semester.

Cynthia Johnson (C.Johnson, personal communication, 11 ${ }^{\text {th }}$ February 2010) a pioneer in developing college programs for students with IDD in the United States, suggests that since many of these students have not been appropriately challenged in mainstream settings, inclusive experiences at a post-secondary level may induce anxiety. As such consideration towards either more flexible approaches such as Universal Design for Learning (CAST, 2010; Gargiulo \& Metcalf, 2010; Raymond, 2008) or multi-level (Salend, 2008) tutorial content appear to be important considerations for university inclusion.

Ryan (2007) suggests that Australian university academics have been "slow to understand and respond to the changing needs of their students" (p.436) and therefore more inclusive, flexible classroom practice may be challenging for many. While it is important to note that tertiary inclusive programs rely on voluntary participation of academic staff, Casale-Giannola and Kamens (2006) reported that without the assistance of a classroom mentor, much of the classroom material would have been inaccessible for the included student. In some subject areas, without inclusive tutorial activities, academic staff may simply become reliant on mentors in the same way that some classroom teachers have become over reliant on Education Assistants within mainstream settings (Giangreco \& Broer, 2007).

\section{Did the inclusion program provide the impetus for Belle to successfully complete an end of unit project?}

The idea of a final presentation was presented to Belle, in lieu of a final exam or assignment and was considered appropriate as she had presented previously in 
Inclusion at university

front of others and felt good about these experiences. The author had liaised with Belle's home support about the presentation and she had worked on it with her university mentors.

The presentation occurred two weeks post the last tutorial and the author, Program Director and three of Belles' mentors were present. Her presentation was well structured, appropriate and delivered in a manner expected at university. Her confidence in front of others was an indicator of her capability with this task. The following are excerpts from her presentation, entitled 'Things I have learnt at university':

I have learnt how to express my feelings at university. Also, university can be quite stressful with difficult hurdles. I have also learnt to communicate and to interact with my friends.

I would like to help other people with Down syndrome and also people with different disabilities. I would like to help them how to express how they feel and to have a good life as well.

I am not a person with a disability or a person who lives in a group home. I live in (suburb name) and I am an individual. I hang out with friends in university. I also go clothes shopping at (shopping centre name). I am now focusing on my own life and studying and I am going to leave any personal problems at home.

The presentation focused on the learning experience for Belle, and reflected a deeper awareness of university, when compared to her earlier thoughts. To acknowledge that university was both a challenging environment and a supportive one via mentors, suggested that she had developed an awareness of the contrast that university presents. Her successful presentation also demonstrated her capacity to achieve set goals within a course situation and highlighted emerging confidence as a result of the experience. The author and Secondary Program Director provided feedback to Belle on her presentation; in both cases it was positive in terms of set outcomes.

\section{What evidence exists that the inclusion program was a positive social and learning experience for Belle?}

Belle's mentors were called upon to reflect on the semester and provide feedback on whether they felt this had been a positive experience for her. The following comments from two of her mentors reveal how many of Belle's aspirations were seen as similar to theirs, but differences in her social interactions were evident;

Student A:

During 2nd semester 2009 at ECU I was privileged to work with Belle. Pretty soon it became clear to me that Belle was a bright, articulate young woman who had many hopes and dreams for her life. She was nervous and excited about attending university, making friends and becoming a successful uni student. In many ways her hopes and dreams echoed my own. During the course of the semester, our friendship grew and I learnt a lot about myself and gained valuable insight into Belle's world. 
Inclusion at university

Student B:

Belle wants to learn; she is very eager to study at university level and wants to make friends along the way. No part of this goal seemed to be outrageous or unrealistic, it was only three years ago that my goals and ambitions were exactly the same as Belle's so I was easily able to relate to this.

Although Belle wanted to be treated like the rest of us, as time went on I think even she realised adjustments needed to be made. The work load was quite intense and she found herself overwhelmed on a few occasions so her main assignment was modified a number of times. There were also quite a few times where Belle said or did things that society would deem as inappropriate so we would explain to her what she was doing and why people do or don't act that way.

There were times when the author at close range witnessed Belle engaging in natural, affirming and positive behaviours inside and outside her classes; other times she appeared confronted and confused by the academic expectations of her participation and the complexities of developing social relationships within this environment.

Experiencing and reflecting on this type of inclusion meant that my involvement was at a more hands-on level than others that may have written about this type of inclusion. However, it was evident that without my intervention, the personal responsibility for successful experiences for Belle would have fallen back to her university mentors (as outlined in Casale-Giannola \& Kamens, 2006). While Belle's challenges with academic aspects of her participation could with ongoing modifications be addressed; it was the social aspects of this experience which provided more difficulties.

For Belle's mentors, the experience was at times a challenging one. Belle was sometimes overzealous in seeking close relationships with her university mentors, and sometimes hasty in her reaction to perceived slights. One of the mentors identified that as much as Belle required assistance with learning, it was they who in turn had to learn and grow:

I knew I was going to be exposed to a whole new perspective and attitude towards those with disabilities. Belle, being in the position she was, already had so much to bring to the unit and although 'we' were going to introduce her to the university environment and way of life, it was clear from the start there was going to be imperative learning on both parts.

Perhaps in Belle's case and for others who may be included into programs at university, experiences of positive inclusion at primary and secondary school would enhance their capacity to develop and sustain relationships.

\section{Conclusion}

Belle's inclusion into university was a learning experience for all involved in the process. Belle expressed her sense of growth in her final presentation and has continued an ongoing relationship with the university. Her mentors developed a realistic and less textbook driven sense of what inclusion can be like, and, more acutely, what a relationship with an individual with IDD feels like within this environment. Whether universities should engage in and promote this type of inclusion requires further discussion. 
Inclusion at university

'Count Me In' (2009) a vision statement for people with disabilities in Western Australia prioritises 'welcoming communities' and 'life-long learning in inclusive settings'. Thoughtful and well structured inclusion for students with IDD into tertiary settings recognises these key principles and potentially "fosters personal confidence and opportunities to build new relationships and interests" (p.16). But simply opening the doors may not be enough. Graham and Slee (2008) sum up the conundrum of inclusion by suggesting; 'into what do we seek to include?' (p.277). While it is apparent that additional staff with background in inclusive practice and more structured support for both the mentor and mentee need to be mobilised to achieve the inclusion of students with IDD on a larger scale (as outlined in Grantley, 2000; Hughson, Moodie \& Uditsky, 2006; Lobban, 2002), it is worth considering what curricular and instructional changes academic staff need to make to truly enable inclusion. While inclusion is never perfect and for many is "about celebrating difference in as dignified manner" (Barton, 1987, p.233); it appears that there are unique opportunities in this environment, along with challenges that may be common to other settings.

The benefits from a social and educational point of view were evident. However, the inclusion of Belle was a time and resource hungry exercise; much planning went into both organising her participation and sustaining her place within the class. With experience and improved structures these factors could be better managed, but a detailed consideration of time costs would be necessary before embarking on a more formal program.

Australian universities appear to be in a state of change. No longer simply for the educational elite, they have been encouraged to open their doors to a much broader cross section of the community. While the exploration of inclusion at a tertiary level is an emerging research topic (Casale-Giannola \& Kamens, 2006; Mosoff, Greenholtz \& Hurtardo, 2009), there is still limited academic literature focused on best practice with students with IDD within university learning environments. Perhaps this is the next step and for now Rachel, a graduate student from the Flinders University 'Up the Hill' project provides the raison d'être for investment of thought and time towards tertiary inclusion. She concluded her end of semester presentation to peers and staff with this:

At uni, I keep meeting people I know from my high school. They are so surprised to see me at uni as a uni student. I have one more year to do at uni; it has been a joyful experience. 
Inclusion at university

\section{References}

Barton, L. (1987). Inclusive education: Romantic, subversive or realistic? International Journal of Inclusive Education, 1 (3), 231-242.

Casale-Giannola, D. \& Wilson-Kamens, M. (2006). Inclusion at a university: Experiences of a young woman with Down Syndrome. Mental Retardation, 44 (5), 344-352.

Centre for Applied Special Technology (C.A.S.T.). (2010). Retrieved June 27, 2011 from http://www.cast.org/

Coffey, A. \& Atkinson, P. (1996). Making sense of qualitative data: Complementary research strategies. London: Sage.

Count Me In: (2009). Count Me In: Disability Future Directions. Disability Services Commission: Western Australia.

Gargiulo, R.M. \& Metcalf, D. (2010). Teaching in today's inclusive classrooms: A universal design for learning approach. U.S.A.: Wadsworth Cengage Learning.

Giangreco, M. \& Broer, S. (2007). School based screening tool to determine overreliance on paraprofessionals. Focus on Autism and Other Developmental Disabilities; 22, 3, 149-158.

Gibson, C.J. (1997). The next step. A pilot study of inclusive university education for selected group of people with an intellectual disability. Unpublished honours thesis. The Flinders University of South Australia.

Graham, L.J. \& Slee, R. (2008). An illusory interiority: Interrogating the discourse of inclusion. Educational Philosophy and Theory, Vol. 40, No. 2, 277-293.

Grantley, J. (2000). Towards inclusion in university of people with intellectual disabilities. International Special Education Conference 2000. University of Manchester. School of Education, Manchester, U.K.

Hart, D., Grigal, M., Sax, C., Martinez, D., \& Will, M. (2006). Postsecondary education options for students with intellectual disabilities. Research to Practice, 45, 1-4.

Hughson, E.A., Moodie, S. \& Uditsky, B. (2006). The story of inclusive postsecondary education in Alberta, final research report 2004-2005. Alberta Association for Community Living.

Living the Dream: Inclusive Post-Secondary Education. (2006). DVD produced by the Alberta Association for Community Living.

Lobban, M. (2002). Taking their place: People with intellectual disability at university. Pathways 6 Conference 2002.

Martinez, D.C. \& Queener, J. (2010). Postsecondary education for student's with Intellectual Disabilities. The George Washington University HEATH Resource Center.

Massaro, V. (2009). Unpicking the Bradley report. The Australian, February 17

Mossoff, J., Greenholtz, J., \& Hurtardo, T. (2009). Assessment of inclusive postsecondary education for young adults with developmental disabilities. Canadian Council on Learning. Retrieved May 20, 2011 from http://www.ccl-cca.ca/pdfs/fundedresearch/Mosoff-FinalReport.pdf

O'Brien, P., Shevlin, M., O’Keefe, M., Fitzgerald, S., Curtis, S. \& Kenny, M. (2009). Opening up a whole new world for students with intellectual disability within a third level setting. British Journal of Learning Disabilities, 37, 285-92 
Inclusion at university

O'Rourke, J. (2005). Academic and social support mechanisms for adolescents with mild disabilities in inclusive classrooms: The development and evaluation of a program. Unpublished Doctoral Dissertation. University of Western Australia.

O'Rourke, J. \& Houghton, S. (2006). Students with mild disabilities in regular classrooms: The development and utility of the Student Perceptions of Classroom Support Scale. Journal of Intellectual and Developmental Disability, 31(4), 232-242.

O'Rourke, J. \& Houghton, S. (2008). Perceptions of secondary school students with mild disabilities to the academic and social support mechanisms implemented in regular classrooms. International Journal of Development, Disabilities \& Education, 55 (3), 227-237.

O'Rourke, J. \& Houghton, S. (2009). The perceptions of secondary teachers and students about the implementation of an inclusive classroom model for students with mild disabilities. Australian Journal of Teacher Education, 34 (1), 23-41.

Raymond, E.B. (2008). Learners with mid disabilities: A characteristics approach. U.S.A: Pearson Education Inc.

Ryan, J. (2007). Learning disabilities in Australian universities: Hidden, ignored, and unwelcomed. Journal of Learning Disabilities, 40 (5), 436-442.

Salend, S. (2008) Creating Inclusive Classrooms. New Jersey: Pearson Prentice Hall

Saloviita, T. (2000). An inclusive adult education program for students with mild to severe developmental disabilities: experiences from a pilot project in Finland. Developmental Disabilities Bulletin, 28, 27-39.

State School Teachers Union of WA inc. (2011). State School Teachers Union of WA (Inc.). Submission paper. Retrieved June 21 from http://docs.google.com/viewer?a=v\&q=cache:THrZObacOZMJ:www.puttingou rkidsfirst.com.au/

Stepping stones. (ND). Retrieved May 23, 2011 from www.flinders.edu.au/shadomx/apps/fms/fmsdownload.cfm?file.

The Bradley Review. (2009). Review of Australian Higher Education. Department of Education, Employment and Workplace Relations: Canberra.

Transforming Australia's higher education system. (2010). Commonwealth of Australia. Retrieved June 21, 2011 from http://www.deewr.gov.au/HigherEducation/Documents/PDF/

Uditsky, B., \& Hughson, A. (2007). Inclusive post-secondary education for students with significant developmental disabilities: challenging legal, moral and pragmatic assumptions. Retrieved May 20, 2011 from National-Louis University Web site: http://www.nl.edu/dse/docs/Uditsky\%20and\%20Hughson.Inclusive\%20postsecondary\%20education.pdf

Weinkauf, T. (2002). College and university: You've got to be kidding: inclusive post-secondary education for adults with intellectual disabilities. Crossing Boundaries, 1 (2), 28-37. 
Inclusion at university

Wolfensberger, W. (2000). A brief overview of social role valorization. Mental Retardation, 38 (2), 105-123

\section{Biographical Note}

John O'Rourke is a senior lecturer in the School of Education at Edith Cowan University, having worked previously as a teacher in secondary schools. He lectures predominately in the area of inclusion and diversity in the classroom. His current research interests include: structures, protocols and support mechanisms that enhance inclusion, happiness and wellbeing in primary aged students, and school-based games technology 